\title{
Synthesis of Ethyl 2-Methylene-3-aryl-4-oxoalkanoates and Ethyl 2-Arylidene-4-oxoalkanoates from the Baylis-Hillman Acetates
}

\author{
Jeong Mi Kim, Yang Jin Im, Taek Hyeon Kim," and Jae Nyoung Kim" \\ Department of Chemistry and Institute of Basic Science, Chonnam Nationat Universin: Kwangit 500-757, Korea \\ ${ }^{\dagger}$ Faculty of Applied Chemistry, Chonnam National Lniversity; Kwangiu 500-757, Korea \\ Recened January 29, 2002
}

Keywords : 2-Methylene-4-oxoalkanoates, 2- $\Lambda$ rylidene-4-oxoalkanoates, Baylis-Hillman acetates.

Recently, we are interested in the nucleophilic substitution reaction of the in situ generated DABCO (1,4-diazabicyclo12.2.2 /octane) salt of the Baylis-lillman acetate.' The $\mathrm{D} \Lambda \mathrm{BCO}$ salt can be prepared in aqueous TIIF instantaneously and completely by simply mixing $\mathrm{D} \wedge \mathrm{BCO}$ and the Baylis-IJilman acetate.' The reaction of the D $\triangle B C O$ salt and nucleophiles such as cyanide, ${ }^{1 \text { " hy }}$ hydride ${ }^{\text {lt }}$ and $p$-toluenesullonamidelc occurted in a $\mathrm{S}_{x} 2^{1}$ lashion selectively.' This two-step reaction can allord a net $S_{* 2}$ type product from the Baylis-f Iillman acctate. Introduction of nucleophiles at the primary position can be carried out by using $\mathrm{K}_{2} \mathrm{CO}_{3}$ in $N, N$ dimethyl formamide (Figure 1).

Recently, Nmri et al. have reported the $S_{12}$ ' reaction of nitronate anion to the Baylis-f Iillman acetate in the presence of $\mathrm{NaO}]\left[\right.$ in T] [F. ${ }^{2}$ They obtained 2-alkylidene-4-nitro ketones in moderate yiclds by using the Baylis-[Jillman adducts derived from methyl vinyl ketone and ethyl vinyl ketone. Eventually, they prepared 2-alkylidene-1,4-diketones via the Nef reaction. ${ }^{2}$ Thus, we intended to examine the reaction of nitronate anion and the Baylis-llillman acetates derived from ethyl acry late or methyl acrylate in order to prepare 2methylene-4-oxoalkanoates or 2-arylidene-4-oxoalkanoates.

$\Lambda$ s reported previously the required DABCO salt of the Baylis-t Iillman acetate could be prepared in sint in aqueous THIF at room temperature within 10 min completely. ${ }^{1}$ In order to generate simultaneously the nitronate anion and the DABCO salt we used two equivalents of DABCO. Nucleophilic substitution reaction of nitronate anion was then carried out at room temperature for 2 days to give 2-methylene-

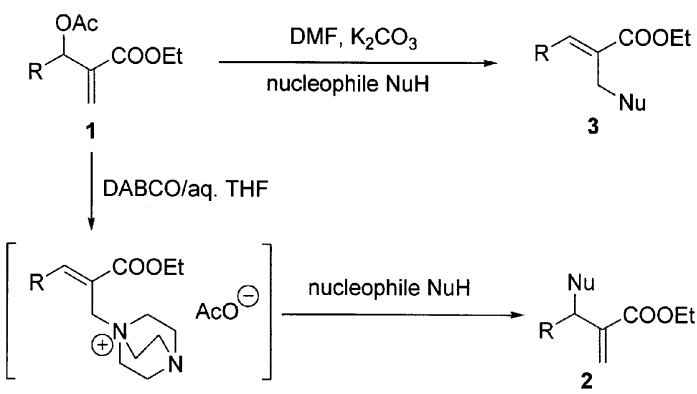

Figure 1

4-nitroalkanoates 2a-e in good yiclds (condition $\Lambda$ ). As shown in Table 1 (entries 1-5), 2a-e was obtained as a mixture of diastereomers. The stereochemistry of syn/anti was not important in the next Nef reaction. Thus, we did not separate the diastereomers in most cases. ${ }^{3}$ In order to prepare 2-arylidene-4-nitroalkanoates 3a-d, reaction of the BaylisI Iillman acelates 1 and primary nitroalkane was carried out in the presence of polassium carbonate in $N, N$-dimethylformamide (condition $B$ ). The stercochemistry of the generated 3a-d was $E$ as previously reported as in other cases. ${ }^{\text {I.4 }}$

We examined next the possibility of converting 2-methylenc-4-nitroalkanoate 2 and 2-arylidene-4-nitroalkanoates 3 into the corresponding ketone derivatives $\mathbf{4}$ and $\mathbf{5}$ via the Nef reaction. However, we could not obtain the desired compounds in appreciable amounts with various known methods such as potassium permanganate, cerium ammonium nitrate, or tin chloride. Best results were observed when we used
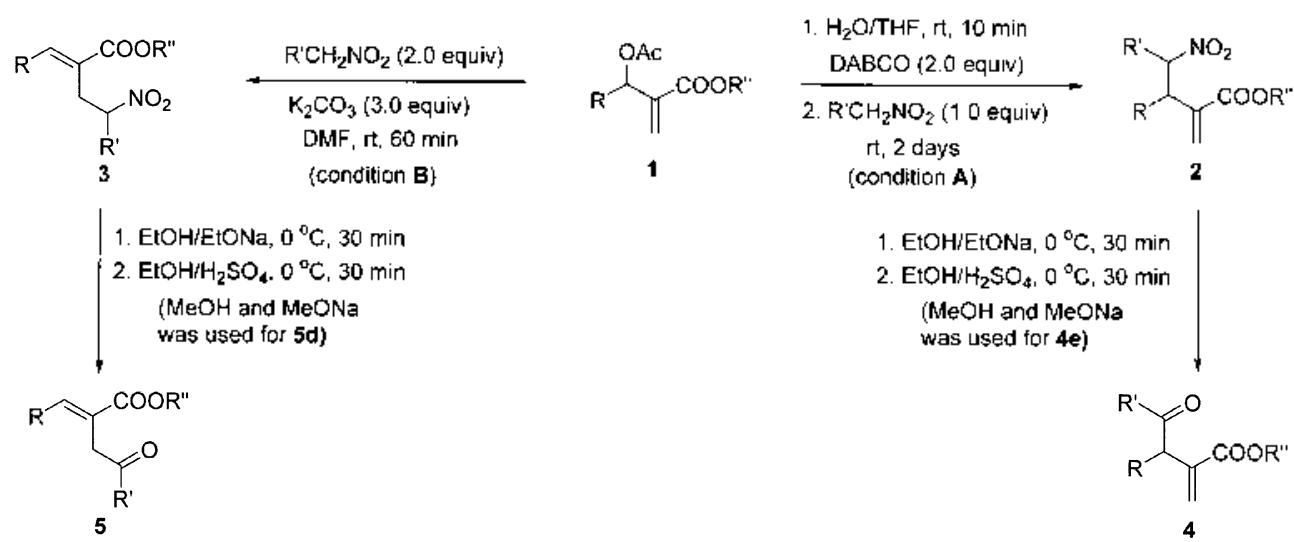

Scheme 1 
Table I. Synthesis of 2-methylene-4-oxoalkanoates 4 and 2-alky|idene-4-oxoalkanoates 5

Entry $\mathrm{B}$ - $\mathrm{Hacctate}(1)$ Conditions

"The ratio ol" sin anti was delermined in 'II NMR spectrum (see ref. 3). brace annouts of 3-alkyl-4-aryl-6H-|1.2 |oxacine-5-carboxylates wete observed. "MeOH/MeONa was used.

the following reaction conditions: treatment of 2 and 3 with sodium alkoxide followed by acidic hydrolysis (Amris condition). ${ }^{2}$

Synthesis of ethyl 2-methylene-3-phenyl-4-oxopentanoate (4a) is typical: To a stirred solution of the Baylis-Hillman

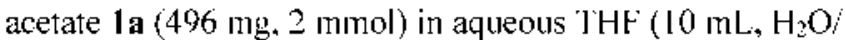
$\mathrm{THF}=\mathrm{l}: \mathrm{l})$ was added $\mathrm{DABCO}(448 \mathrm{mg}, 4 \mathrm{mmol})$ and stirred at room temperature for $10 \mathrm{~min}$. To this solution was added dropwise the solution of nitroethane $(150 \mathrm{mg}, 2$ mınol) in IHF ( $1 \mathrm{~mL}$ ) during $10 \mathrm{~min}$ and stirred at room temperature for 2 days. After the usual workup process and column chromatographic purification we could obtain the desired compound $\mathbf{2 a}$ in $96 \%$ yield ( $505 \mathrm{mg}$ ) as a diastereomeric mixtures $(1: 2) .{ }^{i .6}$ 'to the solution of $2 \mathbf{a}(263 \mathrm{mg}, \mathrm{I}$ mınol) in dry ethanol ( $2 \mathrm{~mL}$ ) was added sodium ethoxide solution (340 $\mathrm{mg}, 1.1 \mathrm{mmol}, 21 \%$. Aldrich) and stirred at 0 ${ }^{\circ} \mathrm{C}$ for $30 \mathrm{~min}$. Pouring the reaction mixture into ethanolic sulfuric acid solution at $0^{\circ} \mathrm{C}$ and stirred during $30 \mathrm{~min}$. After appropriate workup process and column chromatographic purification (hexane/ether, $20: 1$ ) we could obtain 4 a in $40 \%$ isolated yield $(93 \mathrm{mg})^{6}$

In this communication, we disclosed a facile synthesis of two types of $\gamma$ ketoesters. Extension to the $\gamma$ ketoalkanenitrile system and the reaction with other nitro compounds including ethyl nitroacetate are understudy.

Acknowledgment. This work was supported by the grant (No. R02-2000-00074) from the Basic Research Program of the Korea Science \& Fongineering Foundation.

\section{References and Notes}

1. (a) Chung. Y. M.: Gong. J. H.: Kim. T. H.: Kim. J. N. Tetrathedron latt. 2001. +2. 9023. (b) In. Y. J.: Kitm. J. M.: Muns. J. H.: Kim. J.

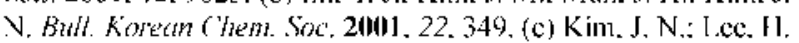
J.: I 心. K, Y.: Gong. J. H. Sintett 20112. 173.

2. (a) Chamakh, A.: Mhirsi. M.: Villieras, J.: l.ebreton. J.: Amri. II. Symhesis 2000. 295. (b) Hbaieb. S.: Amri. H. J. Soc. Chim. Tunis. 2000. 4.671 .

3. Assignment of the ratio of syn anti was impossible due to similar coupling constant between the fwo protons at the 3-and 4-position of 2 . As an example, the two isomers of 2 a were separated in 52 and $24 \%$ respectively. Coupling comstant $f$ of major imomer is $11.2 \mathrm{H} z$ and $11.6 \mathrm{H} z$ for minor isomer:" In other cases the ratio was determined in their 'H NMR spectra and used without separation.

4. The stercochemistry of 5 a-d was $L$ as that of 3 a-d. During the Nef' reaction the stereochemistry was retained. In 'II NMR spectro the vinyl peaks appeared at $7.86-8.08 \mathrm{ppm}$. which was well coincidence with the reported data of similar compounds. ${ }^{2}$

5. Conditions for the Nel reaction. see: (a) Cookson. R. C.: Ray. I'. S. Tetrothedrot lett. 1982. 23. 3521. (b) Das. N. B.: Sarma. J. C.: Sharma. R. P.: Bordoloj. M. Tetretinedron Le'tt. 1993, 34. 869. (c)

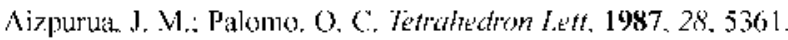
(d) Shechter, I1.: Williams. I: l. J. Org. ("hem. 1962.27. 3699. (e) Mcmurry. J. E.: Melion. J.: Padgetl. H. J. Org. Chem. 1974. 39. 259.

6. Some representative spectroscopic data of $\mathbf{2 a}$. 4a. $3 \mathbf{l}$. and $\mathbf{5} \mathbf{d}$ are as follows.

2x: Major isomer, $52 \%: R_{f}=0,20$ (hexane ether. $8: 1$ ); white solid

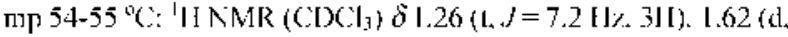
$J 6.5 \mathrm{~Hz} .3 \mathrm{H}$ ). $4.17(\mathrm{q} . J \quad 7.2 \mathrm{~Hz} .2 \mathrm{H}) .4 .38$ (d. $J 11.2 \mathrm{H} z$. $1 \mathrm{H}) .5 .48$ (qd. $J \quad 11.2$ and $6.5 \mathrm{H}<.1 \mathrm{H}$ ). 5.79 (s. $1 \mathrm{H}) .6 .37$ (s. $1 \mathrm{H}$ ). $7.22-7.30(\mathrm{~m} .5 \mathrm{H}):{ }^{1:} \mathrm{C}$ NMR $\left(\mathrm{CDCl}_{3}\right) \delta 14.04 .18 .95 .52 .22$. $61.33,85.67,127.27,127.77,127,99,128.71,137.44,139.37$. 165.76. Minor isomer, $24 \%: \mathrm{R}_{\mathrm{t}}=0.26$ (hexane/ether, $8: 1$ ): oil: ${ }^{1} \mathrm{II}$ NMR (CDCIs) $\delta 1.22(1 . j=7.1 \mathrm{l}[\% .3 \mathrm{II}) .1 .40(\mathrm{~d} . j=6.6 \mathrm{l} \% .3 \mathrm{H})$. $4.07-4.16(\mathrm{~m} .2 \mathrm{H}) .4 .46$ (d. $J \quad 11.6 \mathrm{~Hz} . \mathrm{lH}) .5 .23(\mathrm{gd} . J 11.6$ and $6.6 \mathrm{H} z . \mathrm{HH}) .5 .90(\mathrm{~s} .1 \mathrm{H}) .6 .35(\mathrm{~s} . \mathrm{HH}) .7 .24-7.36(\mathrm{~m} .5 \mathrm{H}):{ }^{1.3} \mathrm{C}$ V.VR $\left(\mathrm{CDCl}_{3}\right) \delta 14.01 .19 .15 .51 .05,61.16 .85 .11 .124 .55$. 127.90, 128.77, 128.94, 136.74,139.66, 165.48.

4a: oil: IR ( $\mathrm{KIBr}) 1718 \mathrm{~cm}^{-1}:{ }^{1} \mathrm{I}$ NMR $\left(\mathrm{CDCl}_{3}\right) \delta 1.31 \mathrm{lt} . J=7.1$

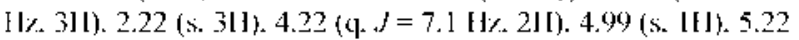
(s. 1H). 6.39 (s. $1 \mathrm{H}) \cdot 7.18-7.40$ (m. 5H): ${ }^{13} \mathrm{C}$ NMR (CDCls) $\delta$ 14.13. 29.66. 60.47. 61.17. 127.90. 129.00. 129.09. 129.66. 134.87. 139.91. 166.69. 205.87.

3d: oil: 'II NMR (CDCl] $) \delta 1.46(\mathrm{~d} . J=6.7 \mathrm{HI}, 3 \mathrm{l}), 2.92-3.00$

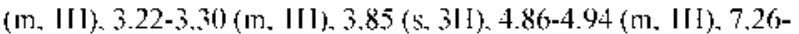
7.42 (m. 5]l). 7.89 (s. 1H): ${ }^{13} \mathrm{C}$ NMR $\left(\mathrm{CDCl}_{3}\right) \delta 18.76 .32 .77$. 52.33. 81.66. 127.24. 128.74. 128.79. 128.95. 134.59. 143.53. 167.64 .

5d: oil: IR (KBr) $1718.1706 \mathrm{~cm}^{-1}$ : ${ }^{1} \mathrm{H}$ NMR (CDCl;) $\delta 2.25$ (s. 3Il) 3.62 (s. 2II) $3.80(\mathrm{~s} .31 \mathrm{I}) .7 .26-7.38(\mathrm{~m}, 5 \mathrm{Il}), 7.93$ (s. III): $\left.{ }^{13} \mathrm{C}, \mathrm{NMR}(\mathrm{CDCl}) \mathrm{3}\right) 30.09,42.54,52.25,126,67,128.62,128.76$. 128.90. 135.07. 142.26. 167.88.206.04. 